\title{
Burkholderia terrae BS001 migrates proficiently with diverse fungal hosts through soil and provides protection from antifungal agents
}

\author{
Rashid Nazir ${ }^{\dagger}$, Diana I. Tazetdinova and Jan Dirk van Elsas* \\ Department of Microbial Ecology, Centre for Ecological and Evolutionary Studies, University of Groningen, Groningen, The Netherlands
}

\section{Edited by:}

Gary M. King, Louisiana State

University, USA

\section{Reviewed by:}

Susannah Green Tringe, Department of Energy Joint Genome Institute, USA

Jizheng He, Chinese Academy of Sciences, China

\section{${ }^{*}$ Correspondence:}

Jan Dirk van Elsas, Department of Microbial Ecology, Centre for Ecological and Evolutionary Studies, University of Groningen,

Nijenborgh 7, 9747 AG Groningen, The Netherlands

e-mail: j.d.van.elsas@rug.nl

${ }^{\dagger}$ Present address:

Department of Environmental Sciences, Commission on Science and Technology for Sustainable Development in the South Institute of Information Technology, Abbottabad, Pakistan
Soil bacteria can benefit from co-occurring soil fungi in respect of the acquisition of carbonaceous nutrients released by fungal hyphae and the access to novel territories in soil. Here, we investigated the capacity of the mycosphere-isolated bacterium Burkholderia terrae BS001 to comigrate through soil along with hyphae of the soil fungi Trichoderma asperellum, Rhizoctonia solani, Fusarium oxysporum, F. oxysporum pv lini, Coniochaeta ligniaria, Phanerochaete velutina, and Phallus impudicus. We used Lyophyllum sp. strain Karsten as the reference migration-inciting fungus. Bacterial migration through presterilized soil on the extending fungal hyphae was detected with six of the seven test fungi, with only Phallus impudicus not showing any bacterial transport. Much like with Lyophyllum sp. strain Karsten, intermediate $\left(10^{6}-10^{8} \mathrm{CFU} \mathrm{g} \mathrm{g}^{-1}\right.$ dry soil) to high ( $>10^{8} \mathrm{CFU} \mathrm{g}^{-1}$ dry soil) strain BS001 cell population sizes were found at the hyphal migration fronts of four fungi, i.e., T. asperellum, Rhizoctonia solani, F. oxysporum and F. oxysporum pv lini, whereas for two fungi, Coniochaeta ligniaria and Phanerochaete velutina, the migration responses were retarded and population sizes were lower $\left(10^{3}-10^{6} \mathrm{CFU} \mathrm{g}^{-1}\right.$ dry soil). Consistent with previous data obtained with the reference fungus, migration with the migration-inciting fungi occurred only in the direction of the hyphal growth front. Remarkably, Burkholderia terrae BS001 provided protection from several antifungal agents to the canonical host Lyophyllum sp. strain Karsten. Specifically, this host was protected from Pseudomonas fluorescens strain $\mathrm{CHAO}$ metabolites, as well as from the anti-fungal agent cycloheximide. Similar protection by strain BS001 was observed for T. asperellum, and, to a lower extent, $F$. oxysporum and Rhizoctonia solani. The protective effect may be related to the consistent occurrence of biofilm-like cell layers or agglomerates at the surfaces of the protected fungi. The current study represents the first report of protection of soil fungi against antagonistic agents present in the soil provided by fungal-associated Burkholderia terrae cells.

Keywords: Burkholderia terrae BS001, mycelial protection, antifungal agents, cycloheximide, bacterial-fungal interactions

\section{INTRODUCTION}

In many natural environments, bacteria and fungi live together in the same microhabitat (Johansson et al., 2004). In such cohabitations, the two partners may have developed strategies to interact with each other, to the mutual success of the interaction (PartidaMartinez and Hertweck, 2005; Partida-Martinez et al., 2007a,b). With basis in their mycelial way of growth, soil fungi are able to cross the air-filled gaps in natural soil (De Boer et al., 2005). Several soil fungi can also facilitate the movement of particular bacteria along the hyphal networks in soil, thus serving as fungal highways (Kohlmeier et al., 2005; Warmink and van Elsas, 2009; Warmink et al., 2011), and further translocate chemical substrates to distant places (serving as fungal pipelines; Furuno et al., 2012a; Banitz et al., 2013; Schamfuß et al., 2013). Concomitantly with

Abbreviations: $\mathrm{CH}$, cycloheximide; OFA, oat flake agar; $\mathrm{cm}$, CHA0 metabolites; cmT, CHA0 metabolites with Trichoderma. the growth of fungi through soil, hospitable niches for the local bacterial communities in the microhabitat at the fungal surface are created (Nazir et al., 2010). Specific bacteria have thus evolved that benefit from such hospitable niches (Haq et al., 2014; Pion et al., 2013). Moreover, fungi proliferating in soil may also serve as agents that enrich and transport particular bacterial species, e.g., pollutant-degrading soil bacteria (Furuno et al., 2010, 2012b; Wick et al., 2007, 2010).

In recent years, soil-colonizing fungi and associated bacteria have gained renewed attention as consortia that may increase the biodegradation potential of soil for recalcitrant pollutants (Banitz etal., 2011a,b, 2012; Harms etal., 2011). Among the various bacterial species present in fungal-affected soil habitats, particular ones, e.g., members of the genus Burkholderia, have been found to be very successful in colonizing the fungal surfaces (Warmink and van Elsas, 2009). Such types may constitute key protagonists of fungal-associated bacterial groups 
(Partida-Martinez et al., 2007a; Warmink and van Elsas, 2009; Warmink etal., 2011; Nazir et al., 2012; Suárez-Moreno et al., 2012). In previous work, (Warmink and van Elsas, 2008), several Burkholderia spp., including Burkholderia terrae, were found to be key inhabitants of the soil underneath the mushroom foot of Laccaria proxima (denoted the mycosphere). Subsequently, similar Burkholderia types were found to be enriched in soil (mycosphere) that is colonized by the saprotrophic fungus Lyophyllum sp. strain Karsten (Warmink and van Elsas, 2009). Moreover, one key strain, Burkholderia terrae BS001, was found to be able to assist other (non-migrating) bacteria, like Dyella japonica BS003, to comigrate with the fungal host (Warmink et al., 2011). Recently, we found that this migration capacity is not restricted to only one species but is spread across several related species of the genus Burkholderia (Nazir et al., 2012). Interestingly, the capability of each Burkholderia species to migrate along with growing fungal hyphae was different in different soils (Nazir et al., 2012).

In a key study on bacterial-fungal symbiosis, Partida-Martinez et al. (2007c) discovered that a remotely related Burkholderia species, Burkholderia rhizoxinica, lives inside the ascomycete Rhizopus microsporus (Partida-Martinez et al., 2007c). Interestingly, the phytotoxins secreted by this fungus are actually produced by the endomycotic Burkholderia rhizoxinica (Partida-Martinez and Hertweck, 2005; Partida-Martinez et al., 2007c). A tight interaction between Burkholderia rhizoxinica and Rhizopus microsporus was shown to exist, as the fungus could not sporulate in the absence of the bacterium (Partida-Martinez et al., 2007c) and the bacterium utilized its type three secretion system (T3SS) to interact with the fungus (Lackner et al., 2009).

In spite of the ecological relevance of the interaction of Burkholderia spp. with soil fungi, we still ignore to what extent this capacity to "ride the fungal highway" is applicable to other fungal hosts, and also what the potential benefit of association with a bacterium like Burkholderia terrae BS001 may be for the latter. Here, we thus extend the previous work on the migration of Burkholderia terrae BS001 along with hyphae of Lyophyllum sp. strain Karsten through soil to a suite of other fungi of ecological relevance, like in biocontrol, pathogenicity and rotting of wood, and also to systems in which fungaladverse conditions reign. We hypothesized that (1) the capacity of Burkholderia terrae BS001 to comigrate with the hyphae of soil fungi is generalistic rather than specific, and (2) soil fungi can obtain benefits from the bacterial cells that associate with their hyphae in terms of enhanced protection from adverse conditions.

\section{MATERIALS AND METHODS GROWTH AND MAINTENANCE OF MICROORGANISMS}

The fungal strains used in this study, i.e., the basidiomycetous Lyophyllum sp. strain Karsten (DSM2979), Rhizoctonia solani AG3, Trichoderma asperellum 302, Coniochaeta ligniaria ATCC44981, Phallus impudicus PI, Phanerochaete velutina PV, Fusarium oxysporum Fo47, and F. oxysporum pv. lini Foln3 were routinely grown on OFA plates, prepared with $30 \mathrm{~g}$ of oat flake (local shop) and $15 \mathrm{~g}$ of agar (Duchefa, Haarlem, Netherlands) in demineralized (milliQ) water to 11 , and sterilized at $121^{\circ} \mathrm{C}$ for $21 \mathrm{~min}$. Once every 4 weeks, the fungal cultures were transferred to fresh OFA plates for maintenance.

The bacterial strains used in this study, i.e., Burkholderia terrae BS001, Pseudomonas tolaasii BS295, Chryseobacterium aurantiacum BS126, Chryseobacterium joostei BS181 and Pseudomonas fluorescens $\mathrm{CHA} 0$, were maintained as frozen cultures in $20 \%$ glycerol $\left(-80^{\circ} \mathrm{C}\right)$. Working stocks were maintained on R2A (Becton, Dickinson and Company, Sparks, MD, USA) agar plates, normally at room temperature, which were streaked onto new plates every week to maintain cell viability. After each third transfer, bacterial cultures were re-established from the original $-80^{\circ} \mathrm{C}$ stock.

\section{SOIL MICROCOSM EXPERIMENTS \\ Preparation of bacterial inocula}

To prepare cell suspensions for inoculation, bacterial strains were grown overnight in $5 \mathrm{ml}$ of Luria-Bertani (LB) broth ( $\mathrm{pH} 7.0$; Sigma-Aldrich, Haarlem) at $23^{\circ} \mathrm{C}$, with shaking. The cells were spun down for $5 \mathrm{~min}$ at $5,000 \times g$, washed and resuspended in $1 \mathrm{ml}$ of sterile saline $(0.85 \% \mathrm{w} / \mathrm{vol} \mathrm{NaCl})$. This procedure was repeated twice. The final cell suspensions were then set to an OD660 of 0.05 (containing an estimated $10^{7}$ cells $\mathrm{ml}^{-1}$, as evidenced using dilution plating on R2A agar). In total, $50 \mu \mathrm{l}$ of each relevant bacterial suspension was used directly for inoculation of soil or agar in the migration experiments.

\section{Bacterial migration through soil with growing fungal hyphae and protection against antifungal agents}

The experimental set-up (in microcosms) served two purposes, i.e., (1) analysis of the comigration behavior of Burkholderia terrae BS001 with the hyphae of different fungal counterparts, and (2) assessment of the putative protective effect against antifungal agents of the presence of strain BS001 on the fungal partner. For both types of analyses, the microcosms consisted of three-compartment Petri dishes (Greiner Bio one, Frickenhausen, Germany), as described elsewhere (Warmink and van Elsas, 2009). Briefly, two of the compartments were filled with pre-sterilized [autoclaved (twice)] Gieterveen $(\mathrm{G})$ soil ( $\mathrm{pH} 4.8$ ). The soil moisture contents corresponded to $60 \%$ of the water holding capacity, the soil bulk density to about $1.3 \mathrm{~g} / \mathrm{cm}^{3}$. A layer of approximately $8 \mathrm{~mm}$ depth was established. The third, non-soil, compartment was filled with OFA and served as a nutrient source for the fungus (Figure S2). The physical barriers between the nutritive and soil compartments prevented compounds from the OFA compartment to reach the soil compartments. The barriers were overcome, though, by fungal hyphae growing out from the OFA compartment into the soil compartments, and hence mycelial fronts progressively extending into the soil were achieved. Triplicate set-ups were used for each of the treatments described in the following. The systems were inoculated, in separate, with each of the aforementioned fungi, by placing agar plugs with fungal mycelium on top of the OFA surface. The systems were incubated at $28^{\circ} \mathrm{C}$, thereby allowing the colonization of the OFA compartment plus the first $1 \mathrm{~mm}$ of the soil (prior to introduction of the bacterial cells). In the experiments, the soil water contents were carefully maintained. 
Following the first incubation period, washed suspensions ( $50 \mu \mathrm{l}$ total) of cells of the inoculant bacterium, i.e., Burkholderia terrae strain BS001, were placed evenly in one 3-mm-wide streak in the soil compartment directly adjacent to (touching) the front of the growing fungal hyphae. Control treatments consisted of the addition of BS001 cells in a similar streak to soil compartments of microcosms without fungal mycelium, and of sterile water added to the fungal-plus microcosms in a similar streak.

For the experiments on co-migration of strain BS001 with different fungal mycelia, the microcosm systems inoculated with both partners were incubated at $23^{\circ} \mathrm{C}$ under constant moisture level, and sampled after 9, 12, 15, and 18 days of inoculation.

For the experiments on the effect of strain BS001 on fungal outgrowth in the presence or absence of antifungal agents in the soil, selected antifungal agents, including cycloheximide $(\mathrm{CH})$, were applied to the soil compartments at a position about $15 \mathrm{~mm}$ away from the mycelial growth front. Following this inoculation, the microcosm systems were incubated at $23^{\circ} \mathrm{C}$, taking care that the soil moisture contents remained at the initial levels. Visual observation of the systems, recording fungal growth, was then performed at regular time intervals, normally every day.

\section{Microscopic observations of the interaction of Burkholderia terrae BS001 with different soil fungi}

To observe the interactions of Burkholderia terrae BS001 with the selected fungi, it was marked with a gene expressing the green fluorescent protein (GFP) using a standard procedure on the basis of plasmid pKH2 (Roelants et al., 2002). In several selected colonies, the gene was found to express very well, as clear green cells could be observed by fluorescence microscopy, whereas the wild-type strain (used as the control) remained uncolored. This gfp-tagged Burkholderia terrae BS001 strain was then used in the observational work on the hyphal-associated BS001 cells.

Confirming previous work, all tests for the presence of Burkholderia terrae BS001 on soil-extracted mycelium consistently yielded negative results, due to the difficulty of obtaining sufficient soil-exposed fungal biomass. To assess the bacterial association with fungal hyphae, we then placed pre-sterilized microscope slide cover slips on the $G$ soil surfaces in the microcosms and let the fungus grow over it (using systems with or without the $g f p$-marked BS001 cells). At several time points following bacterial inoculation, the cover slips were aseptically removed from the systems and subsequently observed by microscopy. For this purpose, an epifluorescence microscope (Zeiss Axiostar Plus) was used, with light of the excitation wavelength entering the sample through the objective lens and the fluorescence emitted by the sample coming to the detector by the same objective used for the excitation.

\section{BACTERIAL POPULATION DYNAMICS IN THE SOIL MICROCOSMS}

Using triplicate systems per treatment, bacterial CFU counts were performed at regular time intervals following bacterial inoculation (see above). For this, samples (about $100 \mathrm{mg}$ ) were punched out (using a 4-mm diameter auger) at different sites within the soil compartments. The sites were selected to cover the migration front, the inoculation site as well as other specified positions in the soil compartments. The soil samples were processed for further analyses by serial tenfold dilution followed by plating onto selected agar media, i.e., R2A (general bacterial count), Gould's S1 (Gould et al., 1985; count of fluorescent pseudomonads, i.e., strain CHA0), and/or PCAT (Burkholderia count; Salles et al., 2005). Plating was followed by incubation of the plates at $28^{\circ} \mathrm{C}$ and CFU counting after incubation for 1-5 days. CFU counts were transformed to counts per g dry soil, indicating the development of population densities of both the Burkholderia terrae and the antifungal bacteria.

\section{TESTING OF GROWTH OF Burkholderia terrae BS001 ON CYCLOHEXIMIDE}

To evaluate if Burkholderia terrae BS001 can grow on $\mathrm{CH}$ as the sole C source, we prepared triplicate 100-ml Erlenmeyer flasks with $20 \mathrm{ml}$ minimal medium (MM) supplemented with $\mathrm{CH}(0-$ $0.5 \%$ ) as the carbon and energy source. As a positive control, MM supplemented with $0.5 \%$ glucose was used. Strain BS001 was then introduced as $10^{6}$ (pre-grown and washed) cells $/ \mathrm{ml}$ into the media, after which flasks were incubated at $28^{\circ} \mathrm{C}$ (with shaking). Growth was measured by visual observation, OD determinations and $\mathrm{CFU}$ counting following dilution plating onto R2A plates.

\section{OFA PLATE INHIBITION EXPERIMENTS}

The protective effect conferred by Burkholderia terrae BS001 upon Lyophyllum sp. strain Karsten and other selected fungi (see results) against the antagonistic pressure exerted by $\mathrm{CH}$ was tested. Different concentrations of $\mathrm{CH}$, i.e., 6, 12.5, 25, 50, 75, and $100 \mu \mathrm{g} / \mathrm{ml}$, were applied to fresh OFA plates. Moreover, 'induced' or 'uninduced' Pseudomonas fluorescens strain CHA0 metabolites (produced as detailed below) were also added. Unamended OFA plates served as controls. All plates were inoculated as follows. Cells of Burkholderia terrae BS001 (about $10^{6}$ per ml; $50 \mu \mathrm{l}$ ) and of selected fungi (plugs) were both placed, either in monoculture or in combination, at specified sites (see Figure S1A) on the plates. This yielded three combinations, i.e., 'fungus-alone,' 'bacteriumalone', and 'fungus + bacterium.' The plates were incubated at $28^{\circ} \mathrm{C}$ and growth of the fungal mycelium over the plate was monitored over time, taking daily measurements, with reference time points at $0,1,7,14,21$, and 28 days following introduction. On the basis of the collective data per treatment, the fungal migration 'progress' was calculated in relation to the presence or absence of the bacterial partner (expressed as mm per day). To monitor the bacterial population densities, the systems were sampled, at regular times, by removal of a small core from the OFA plates and vortex-mixing it for $15 \mathrm{~min}$ in $1 \mathrm{ml}$ sterile saline. The resulting suspensions were then serially (10-fold) diluted and appropriate dilutions plated onto R2A to subsequently enumerate the CFU after 2-4 days of incubation at $23^{\circ} \mathrm{C}$.

Production of a Pseudomonas fluorescens strain CHAO metabolome Pseudomonas fluorescens strain CHA0 metabolites were collected following overnight (approximately 15-16 h) growth of strain CHA0 (inoculum $10^{4}-10^{6}$ cells) at $23^{\circ} \mathrm{C}$ in $\mathrm{LB}$, either singly or in the presence of T. asperellum 302 (see Figure S1A). As 
a negative control, LB without any inoculation, incubated in the same conditions, was used. Cells were spun down from the grown culture to obtain supernatants. These supernatants, constituting the strain CHA0 metabolome, were then filtersterilized $(0.45 \mu \mathrm{m}$ pore size $)$ and used as supplements of the OFA medium, using 1:1 mixing with liquid OFA. In one experiment, the metabolites were thus homogeneously available in the whole plate, while in an additional experiment strain CHA0 metabolites (1:1 with medium) were introduced in a stripe, $15 \mathrm{~mm}$ away from the fungal inoculation site (see Figure S1B). The fungal growth patterns and bacterial dynamics, from both experimental set ups, were then monitored as explained above.

\section{STATISTICS AND DATA ANALYSIS}

All experiments were performed using (at least) triplicate systems per treatment. Several experiments were repeated in time (see Results). At each time point, the (CFU) data were log-transformed, after which average values and standard deviations were calculated (shown between brackets in the text and/or as error bars in the figures).

Comparisons were made by statistical tests ( $t$-test, ANOVA) using the SPSS package (SPSS, IBM, Statistics 1.8 for Windows), and data are reported as significant at $P<0.05$.

\section{RESULTS}

\section{GROWTH OF FUNGAL STRAINS THROUGH G SOIL MICROCOSMS IN RELATION TO THE PRESENCE OR ABSENCE OF Burkholderia terrae BS001}

From the start of the experiments, all fungi, i.e., Lyophyllum sp. strain Karsten, Rhizoctonia solani AG3, Trichoderma asperellum 302, Coniochaeta ligniaria ATCC 44981, Phallus impudicus PI, Phaenerochaete velutina PV, Fusarium oxysporum Fo47 and F. oxysporum pv. lini Foln3 grew steadily as a hyphal front over the OFA compartment, and from that into the G soil compartments. Subsequently, the fungal hyphal fronts, visualized by mostly whitish mycelium at the soil surface, extended progressively through the soil compartments until reaching the edges of the plates. It should be noted that the movement of the two Fusarium spp. could be monitored for up to $20 \mathrm{~mm}$, after which the growth fronts became very difficult to visually detect. Hyphal extension was irreverent of the presence of Burkholderia terrae BS001 cells, as for none of the fungi, any noticeable or significant inhibition of growth by the presence of Burkholderia terrae BS001 was found, as compared to the controls $(P>0.05)$. As judged from observing the rates of migration of the hyphal fronts, the growth patterns of the fungi through the soil compartments were significantly different for several of the species tested. Thus T. asperellum 302 exhibited the highest growth rate, i.e., $4.5 \pm 0.2 \mathrm{~mm} /$ day, while Phaenerochaete velutina $\mathrm{PV}$ was the slowest grower, i.e., $0.8 \pm 0.1 \mathrm{~mm} /$ day. The other fungi, i.e., Lyophyllum sp. strain Karsten, Coniochaeta ligniaria ATCC44981, Rhizoctonia solani AG3 and both Fusarium spp. (Fo47 and Foln3), showed intermediate growth rates, i.e., $1.6 \pm 0.24,1.14 \pm 0.16,1.28 \pm 0.13$, and $1.5 \pm 0.11 \mathrm{~mm} /$ day, respectively. Finally, Phallus impudicus PI grew only very poorly into the soil matrix, with a rate close to zero over experimental time.

\section{MIGRATION OF Burkholderia terrae BSO01 ALONG WITH THE HYPHAL GROWTH FRONTS THROUGH G SOIL}

As expected, Burkholderia terrae BS001 migrated along with the developing hyphae of Lyophyllum sp. strain Karsten (used as the reference fungus) through the G soil, establishing a population density of over $10^{8} \mathrm{CFU} / \mathrm{g}$ dry soil at the migration front (18 days; see Table 1). With six out of the seven other fungi, strain BS001 showed similar behaviour, i.e., migration with the developing fungal hyphae in the canonical growth direction of the fungi but not in the reverse direction (densities below the detection limit), albeit with different cell densities at the end of the experimental period at the migration fronts. For example, F. oxysporum Fo47 also supported $>10^{8} \mathrm{CFU} / \mathrm{g}$ dry soil of Burkholderia terrae BS001 at the hyphal fronts, while Rhizoctonia solani AG3, T. asperellum 302 and F. oxysporum pv lini Foln3 supported population densities of $10^{6}-10^{8} \mathrm{CFU} / \mathrm{g}$ dry soil. These densities apparently constituted the carrying capacities of the fungus/soil combinations in the microcosm systems used. In this respect, Burkholderia terrae BS001 showed migration to low densities during the same time course (18 day) at the migration fronts (i.e., in the range $10^{3}-10^{5} \mathrm{CFU} / \mathrm{g}$ dry soil) of Coniochaeta ligniaria ATCC44981 and Phaenerochaete velutina PV. These numbers were significantly lower than those found with the aforementioned fungi $(P<0.05)$. Finally, Burkholderia terrae BS001 could not be shown to firm a clear association, resulting in comigration, with the (poorly migrating) Phallus impudicus PI hyphae.

\section{ASSOCIATION OF Burkholderia terrae BS001 CELLS WITH FUNGAL HYPHAE}

As outlined in Materials and Methods, revealing the presence of Burkholderia terrae BS001 biofilms or cell agglomerates directly on soil-dwelling mycelium was technically too demanding. Using the cover slip soil incubation method instead (4-5 days following the start of the experiment), gfp-marked (or unmarked) Burkholderia terrae BS001 cells could be shown to become associated, as layers or agglomerates of cells, with the growing hyphae away from the inoculation sites of all fungi except F. oxysporum pv lini Foln3 and Phallus impudicus PI. These observations were consistent with the positive strain BS001 CFU counts. Thus, the mycelial networks in soil of Phaenerochaete velutina PV, $T$. asperellum 302, Rhizoctonia solani AG3, F. oxysporum Fo47, and Coniochaeta ligniaria ATCC44981, next to the reference fungus Lyophyllum sp. strain Karsten, had all been colonized by strain BS001 cells. The levels of colonization were diverse for the different fungal hosts, with either layers of cells (e.g., $T$. asperellum 302) or isolated cell agglomerates (e.g., F. oxysporum Fo47) being visible. Figure 1 shows the colonization of the growing hyphae of the selected fungi by Burkholderia terrae BS001 cells.

\section{PROTECTIVE EFFECT OF Burkholderia terrae BS001 TO HOST FUNGI Protection provided by Burkholderia terrae BS001 to Lyophyllum sp. strain Karsten against antifungal agents in soil}

First, the selected strains Pseudomonas fluorescens CHA0, Pseudomonas tolaasii BS295, Chryseobacterium aurantiacum BS126, and Chryseobacterium joostei BS181 revealed to be antagonistic 
Table 1 | Migration of Burkholderia terrae BS001 through soil along the hyphae of different fungi.

\begin{tabular}{llll}
\hline Fungal species & Ecological feature & Hyphal type & Level of migration* (CFU/g dry soil) \\
\hline Lyophyllum sp. strain Karsten & Saprotroph & Thread-like mycelia & +++ \\
Rhizoctonia solani AG3 & Phytopathogen & Thread-like mycelia & ++ \\
Trichoderma asperellum 302 & Biocontrol & Thread-like mycelia & ++ \\
Fusarium oxysporum Fo47 & Phytopathogen & Thread-like mycelia & +++ \\
F. oxysporum pv. lini Foln3 & Biocontrol & Thread-like mycelia & ++ \\
Coniochaeta ligniaria ATCC 44981 & Saprotroph, avid organic & Thread-like mycelia & + \\
& matter degrader & & - \\
Phallus impudicus PI & Wood rot & Cords & + \\
Phaenerochaete velutina PV & Wood rot & Cords &
\end{tabular}

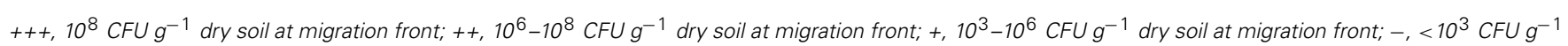
dry soil at migration front.

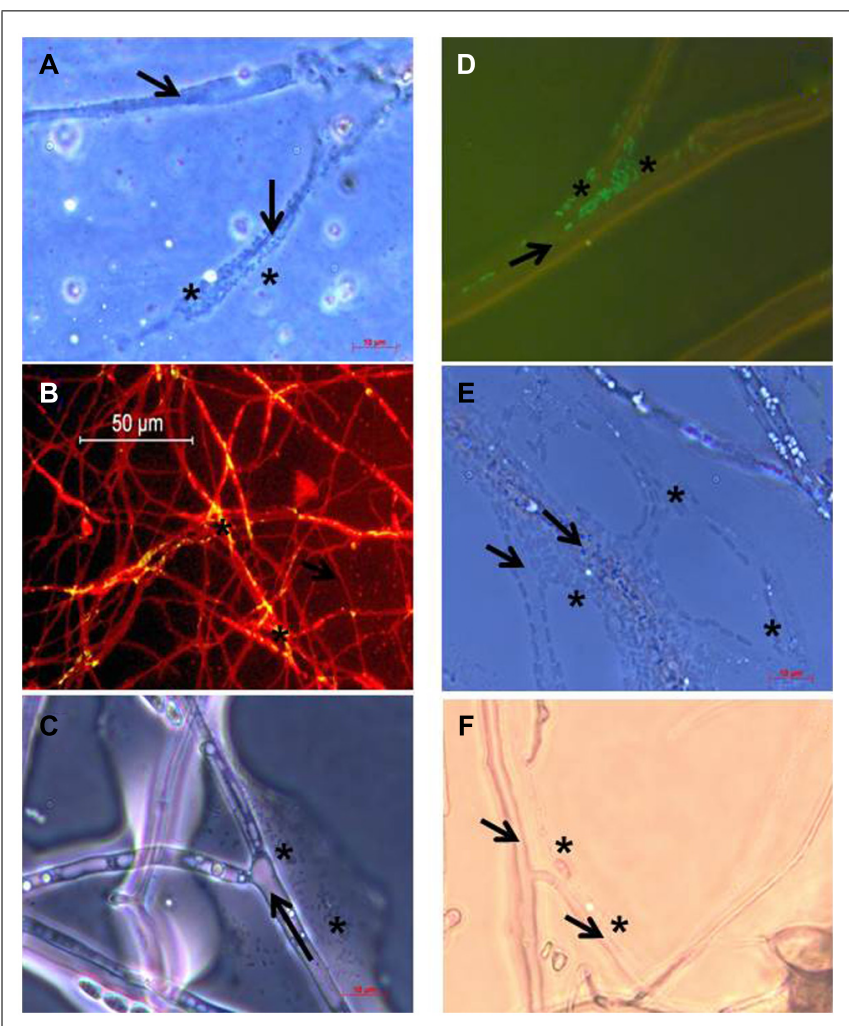

FIGURE 1 | Microscopic images of the association of Burkholderia terrae BS001 cells with mycelium of: (A) Phaenerochaete velutina PV, (B) Trichoderma asperellum 302, (C) Rhizoctonia solani AG3, (D) Fusarium oxysporum Fo47, (E) Coniochaeta ligniaria ATCC44981 and (F) Lyophyllum sp. strain Karsten. Arrows indicate the fungal hyphae, and asterisks indicate the presence of bacterial cell agglomerates. Microscopic observation was supported by differential staining with FITC (fungus) and acridine orange (strain BS001; B) or the green fluorescent protein (GFP; C).

(growth-inhibiting), much like $\mathrm{CH}$, to Lyophyllum sp. strain Karsten growing in dual-plate assays (data not shown). These four bacterial strains as well as the antifungal agent $\mathrm{CH}$ were thus used in a soil microcosm set-up.
In the microcosm compartments containing the presterilized $\mathrm{G}$ soil, the population densities of all antagonists, introduced at the onset about $15 \mathrm{~mm}$ away from the Lyophyllum sp. strain Karsten mycelial fronts, persisted at about the inoculum levels, i.e., about $10^{6}$ CFU per g dry soil, over the experimental time. Remarkably, Lyophyllum sp. strain Karsten was not able to grow over the sites where these bacterial antagonists had been applied (shown after 15 days; Figure S2), whereas it grew 'normally' through control G soil without the added antagonists. However, in all cases in which Burkholderia terrae BS001 had been introduced at the young mycelial fronts (about $5 \times 10^{6}$ cells per $g$ of soil), the fungal soil invader was able to grow over the soil zone where the antagonists were present (Figure S2), albeit in a retarded fashion $(P<0.05)$ as compared to the non-antagonist controls (see Table 2). Similar findings were obtained when the mycelial growth fronts were confronted with $25 \mu \mathrm{g} / \mathrm{g}$ dry soil of $\mathrm{CH}$ in the soil. Overall, the protective effect of Burkholderia terrae BS001 to Lyophyllum sp. strain Karsten was most prominent with Chryseobacterium aurantiacum BS126, as the fungal growth rate over the antagonistic zone was highest, i.e., $1.57 \pm 0.10$. Lower protective effects were seen with the other antagonists as well as with $\mathrm{CH}$ (Table 2). In the case of strain BS126, the fungal growth rates with strain BS001 and over the antagonistic regions were similar $(P>0.05)$ to those of the controls (no antagonist, with or without strain BS001). With respect to the other antagonists (including $\mathrm{CH}$ ), the presence of Burkholderia terrae BS001 significantly lifted the fungal growth rates $(P<0.05)$, 'rescuing' the fungus. However, this resulted in a reduced fungal growth rate as compared to the controls $(P<0.05)$.

\section{Protective effect of Burkholderia terrae strain BS001 against the Pseudomonas fluorescens strain CHAO metabolome}

Strain CHA0 is a known antagonist of soil fungi, and it inhibited Lyophyllum sp. strain Karsten in a dual-plate assay. Figure 2 shows the results of OFA plate experiments with the strain CHA0 metabolome. The presence of metabolites of both singly grown and ' $T$. asperellum 302-grown' Pseudomonas fluorescens CHA0 significantly inhibited the growth of Lyophyllum sp. strain Karsten on OFA, as compared to growth 
Table 2 | Effect of Burkholderia terrae BS001 on the migration of $L$. sp. strain Karsten through soil as affected by the presence/absence of antifungal agents (bacterial strains and $\mathrm{CH}$ ).

\begin{tabular}{|c|c|c|c|c|c|c|c|}
\hline \multicolumn{2}{|c|}{ Antifungal agent present } & \multirow{2}{*}{$\begin{array}{l}\text { Control } \\
1.66(0.06)^{\mathrm{a}}\end{array}$} & \multirow{2}{*}{$\frac{\mathbf{C H}}{1.57(0.07)^{\mathrm{a}}}$} & \multirow{2}{*}{$\frac{{ }^{\text {BS126 }}}{1.55(0.03)^{\mathrm{a}}}$} & \multirow{2}{*}{$\begin{array}{l}\text { BS181 } \\
1.64(0.07)^{\mathrm{a}}\end{array}$} & \multirow{2}{*}{$\begin{array}{l}\text { BS295 } \\
1.68(0.07)^{\mathrm{a}}\end{array}$} & \multirow{2}{*}{$\begin{array}{l}\text { CHAO } \\
1.57(0.03)^{\mathrm{a}}\end{array}$} \\
\hline No & without BS001 & & & & & & \\
\hline \multirow[t]{2}{*}{ Yes } & without BS001 & $1.64(0.03)^{\mathrm{a}}$ & $N D^{b}$ & $N D^{b}$ & $N D^{b}$ & $N D^{b}$ & $N D^{b}$ \\
\hline & with BS001 & $1.68(0.03)^{\mathrm{a}}$ & $1.15(0.10)^{c}$ & $1.57(0.10)^{\mathrm{a}}$ & $1.31(0.10)^{c}$ & $1.31(0.10)^{\mathrm{c}}$ & $1.26(0.17)^{\mathrm{c}}$ \\
\hline
\end{tabular}

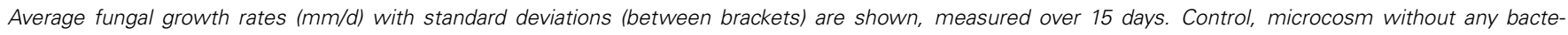

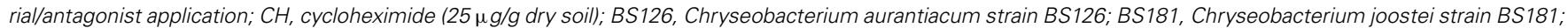

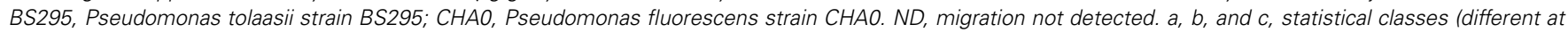
$P<0.05)$.

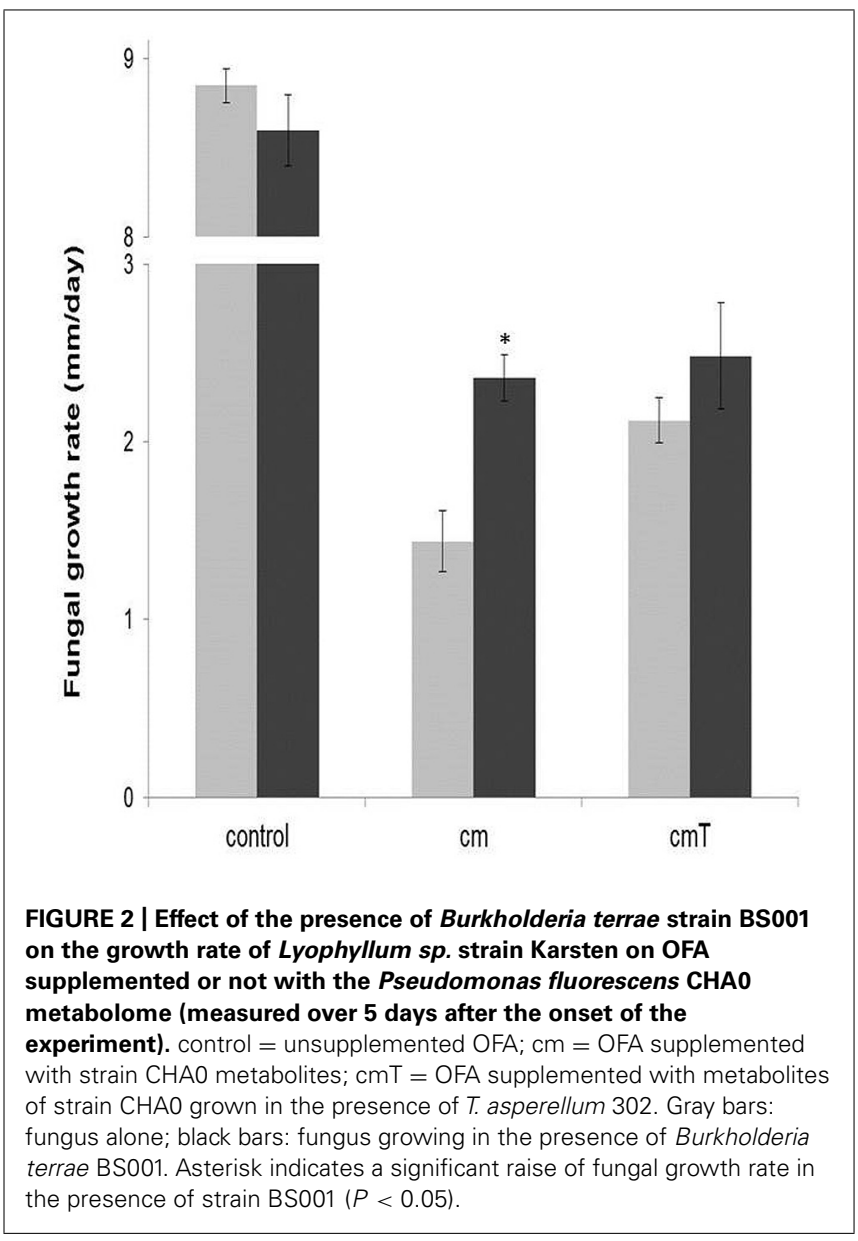

on unamended OFA $(P<0.05)$. Moreover, the presence of Burkholderia terrae BS001 cells on the OFA amended with singly grown strain CHA0 metabolites incited a significant $(P<0.05)$ increase in the growth rate of Lyophyllum sp. strain Karsten on this medium, as compared to its growth without BS001 (Figure 2, treatment $\mathrm{cm}$ ). Whereas a trend toward a similar effect was found for metabolites from strain CHA0 grown in the presence of T. asperellum 302, this was not significant $(P>0.05)$.
In the light of the probably tight interaction of Burkholderia terrae BS001 with the biocontrol fungus T. asperellum 302 (Figure 1), we extended the analysis of the potential protective effect exerted by Burkholderia terrae BS001 to this fungus. Indeed, observations made after both 4 and 5 days of incubation indicated that $T$. asperellum 302 was significantly inhibited in its outgrowth on OFA plates in the presence of strain CHA0 metabolites obtained from singly grown or T. asperellum 302 grown strain BS001 cells $(P<0.05$; Figure 3$)$. Remarkably, the protective effect of Burkholderia terrae BS001 to this fungal host was only significant when Burkholderia terrae BS001 cells were introduced at the fungal hyphae with a 1 -day delay $(P<0.05)$, whereas no significant effect was detected in systems where Burkholderia terrae BS001 had been co-inoculated with the fungus (Figure 3). We further observed a reduction of spore formation (green zones within the T. asperellum 302 older mycelium) on OFA amended with the strain CHA0 metabolome as compared to the controls. This effect was stronger with metabolites from T. asperellum $302-$ grown CHA0 cells than with those from the singly-grown CHA0 cells (Figure S3), indicating a possible sporulation-inhibiting effect of its metabolites. Interestingly, the presence of strain BS001 at the hyphal network alleviated the effect of such metabolites on sporulation of T. asperellum 302. Figure S3 contains the details of this observation.

\section{Protective effect of Burkholderia terrae strain BSO01 against cycloheximide}

Effect on Lyophyllum sp. strain Karsten and T. asperellum 302. First, we investigated whether Burkholderia terrae BS001 could grow in $\mathrm{MM}$ with $\mathrm{CH}$ as the sole $\mathrm{C}$ source, thus diminishing or abolishing the inhibitory action of $\mathrm{CH}$. The BS001 cell densities (as CFUs) remained roughly at the initial level even after 1 month of incubation at $28^{\circ} \mathrm{C}$ (shaking). In the positive control flasks (MM supplemented with $0.5 \%$ glucose), strain BS001 showed vigorous growth after only 2 days at $28^{\circ} \mathrm{C}$. Thus, Burkholderia terrae BS001 was not found to grow at the expense of $\mathrm{CH}$ in $\mathrm{MM}$, which rules out the possibility of $\mathrm{CH}$ removal but leaves that of transformation into a (possibly less toxic) product.

The potential of Burkholderia terrae BS001 to protect Lyophyllum sp. strain Karsten from $\mathrm{CH}$ was then tested using a $\mathrm{CH}$ concentration range $(0-100 \mu \mathrm{g} / \mathrm{ml})$ in OFA plates. Unamended 


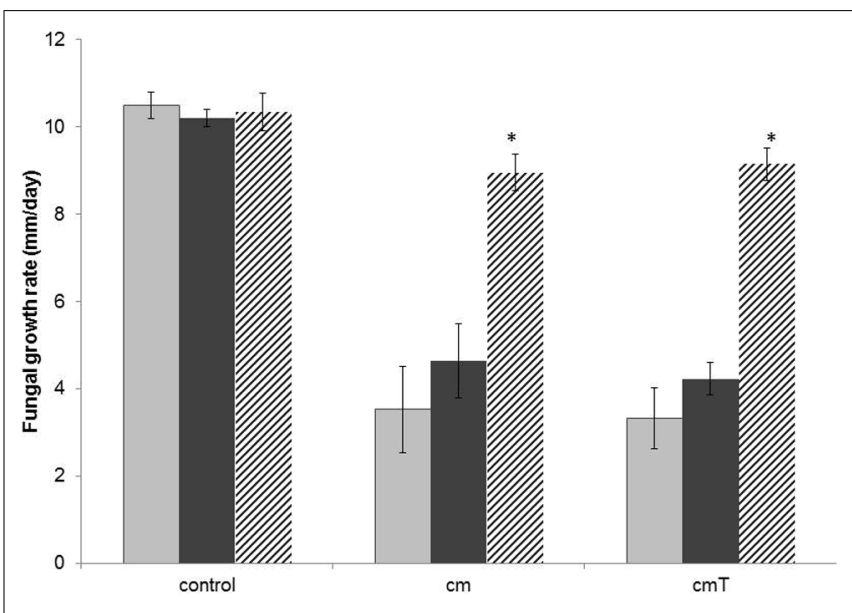

FIGURE 3 | Effect of the presence of Burkholderia terrae strain BS001 on the growth rate of $T$. asperellum 302 on OFA supplemented or not with the Pseudomonas fluorescens CHAO metabolome (measured over 4 days after the onset of the experiment). Explanation:

control = unsupplemented OFA; $\mathrm{cm}=$ OFA supplemented with strain $\mathrm{CHAO}$ metabolites (singly grown $\mathrm{CHAO}$ ); $\mathrm{cmT}=$ OFA with metabolites of strain $\mathrm{CHAO}$ grown in the presence of $T$. asperellum 302. Gray bars: fungus alone; black bars: fungus growing in the presence of Burkholderia terrae BS001. Striped bars: fungus growing in the presence of Burkholderia terrae BS001, with Burkholderia terrae BS001 introduced at the hyphal front $24 \mathrm{~h}$ after the onset of the experiment. Asterisks: significant raises of growth rates in the presence of strain BS001 ( $P<0.05)$.

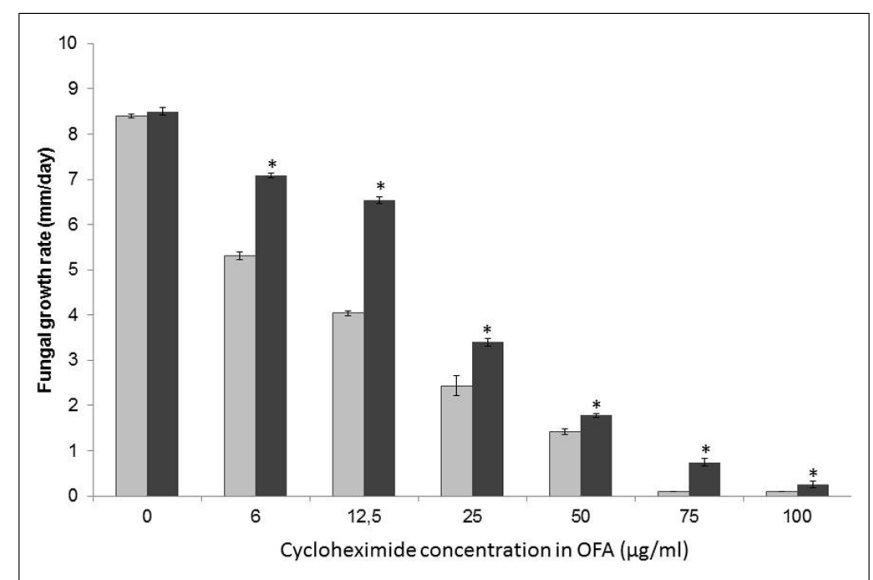

FIGURE 4 | Effect of the presence of Burkholderia terrae strain BS001 on the growth rate of Lyophyllum sp. strain Karsten on OFA supplemented or not with different concentrations of $\mathrm{CH}$. Data represent observations after 25 day of incubation; growth at 75 and $100 \mathrm{ug} / \mathrm{ml} \mathrm{CH}$ was recorded as from day 21. Gray bars: fungus alone; black bars: fungus growing in the presence of Burkholderia terrae BS001.

Asterisks: significant raises of fungal growth rates in the presence of strain BS001 $(P<0.05)$.

OFA allowed fungal outgrowth, from the inoculation site, at about $8.5 \mathrm{~mm} /$ day both without and with strain BS001 cells (Figure 4), whereas the presence of $\mathrm{CH}$ in all tested concentrations was clearly detrimental to hyphal outgrowth. The inhibitory effects exerted by $\mathrm{CH}$ were significant in all cases and became progressively stronger with increasing $\mathrm{CH}$ levels $(P<0.05)$. Specifically, 6 and $12.5 \mu \mathrm{g} / \mathrm{ml} \mathrm{CH}$ reduced the growth rates to
$5.31 \pm 0.08$ and $4.07 \pm 0.03 \mathrm{~mm}$ /day, respectively. $\mathrm{CH}$ levels of 25 and $50 \mu \mathrm{g}$ per $\mathrm{ml}$ further reduced these rates to $2.44 \pm 0.22$ and $1.42 \pm 0.02 \mathrm{~mm} /$ day. The presence of 75 and $100 \mu \mathrm{g}$ of $\mathrm{CH}$ per $\mathrm{ml}$ of OFA inhibited fungal growth completely, and growth arrest lasted for up to 3 months following inoculation (Figure 4).

Very interestingly, the presence of Burkholderia terrae BS001 cells (introduced at about $10^{6}-10^{7} \mathrm{CFU}$ ) adjacent to the Lyophyllum sp. strain Karsten hyphal front significantly reduced the inhibitory effect of $\mathrm{CH}$ in the OFA on fungal growth. Although different in magnitude, the effect was significant $(P<0.05)$ for all used $\mathrm{CH}$ concentrations (Figure 4, indicated by asterisks). Specifically, the fungal growth rates were $5.31 \pm 0.03,4.047 \pm 0.01$, $2.44 \pm 0.22$, and $1.42 \pm 0.028 \mathrm{~mm} /$ day with $6,12.5,25$, and $50 \mu \mathrm{g} / \mathrm{ml} \mathrm{CH}$ in the absence of strain BS001, while these were significantly $(P<0.05)$ raised, to respectively, $7.04 \pm 0.05,6.5 \pm 0.05$, $3.42 \pm 0.02$, and $1.78 \pm 0.02 \mathrm{~mm} /$ day in the presence of Burkholderia terrae BS001 (Figure 4). Furthermore, the highest $\mathrm{CH}$ levels (i.e., 75 and $100 \mu \mathrm{g} / \mathrm{ml}$ ) were initially detrimental to Lyophyllum $s p$. strain Karsten growth, even in the presence of Burkholderia terrae BS001. However, in the presence of Burkholderia terrae BS001, the fungus started to grow visibly after 21 day on the amended OFA plates and the presence of Burkholderia terrae cells had a large and significant positive effect on fungal growth rate afterward, being $0.74 \pm 0.08(75 \mu \mathrm{g} / \mathrm{ml})$ and $0.25 \pm 0.07(100 \mu \mathrm{g} / \mathrm{ml})$ $\mathrm{mm} /$ day. In the absence of the bacterium, fungal growth was completely abolished even 84-90 day following fungal inoculation (Figure 4).

We then evaluated the protective effect of Burkholderia terrae BS001 on T. asperellum 302 under $\mathrm{CH}$ pressure in OFA. First, similar to Lyophyllum sp. strain Karsten, $\mathrm{CH}$ at varying levels significantly inhibited the growth of T. asperellum 302 as compared to the zero-control $(P<0.05$; not shown). No effect of the presence of Burkholderia terrae BS001 cells could be found at 50 and $75 \mu \mathrm{g} / \mathrm{ml} \mathrm{CH}(P>0.05)$. However, at $100 \mu \mathrm{g} / \mathrm{ml} \mathrm{CH}$, strain BS001 cells again significantly protected the fungal hyphae $(P<0.05)$, resulting in a raised fungal growth rate $(2.35 \pm 0.09 \mathrm{~mm} /$ day $)$ compared to the fungus growing without added bacterial cells $(1.90 \pm 0.07 \mathrm{~mm} /$ day $)$.

Effect on other fungi. The growth rates of Rhizoctonia solani AG3 and F. oxysporum pv lini FoLn3 on OFA plates under $\mathrm{CH}$ pressure were also evaluated in relation to the effect of Burkholderia terrae strain BS001. The growth of both fungi was significantly $(P<0.05)$ inhibited by the presence of 75 and $100 \mu \mathrm{g} / \mathrm{ml}$ of $\mathrm{CH}$, whereas lower concentrations permitted fungal outgrowth rates similar to the (zero- $\mathrm{CH}$ ) control. The growth of Rhizoctonia solani AG3, over 7 days, occurred at rates of $3.85 \pm 0.212$ and $4.75 \pm 0.353 \mathrm{~mm} /$ day, in the presence of 75 and $100 \mu \mathrm{g} / \mathrm{ml}$ $\mathrm{CH}$, while the growth rate was $8.5 \pm 0.015 \mathrm{~mm} /$ day in the zero$\mathrm{CH}$ controls. Burkholderia terrae BS001 did protect Rhizoctonia solani AG3 from the growth-inhibiting effect of $\mathrm{CH}$ to a significant extent $(P<0.05)$. In the presence of strain BS001, the fungal growth rates over 7 day were $5.15 \pm 0.24$ and $5.1 \pm 0.08 \mathrm{~mm} /$ day, respectively, on OFA amended with 75 and $100 \mu \mathrm{g} / \mathrm{ml} \mathrm{CH}$, versus the aforementioned rates of $3.85 \pm 0.21$ and $4.75 \pm 0.35 \mathrm{~mm} /$ day (Figure S4). 
With respect to $F$. oxysporum pv lini, the growth rate over 7 days in zero- $\mathrm{CH}$ condition was $8.35 \pm 0.01 \mathrm{~mm} /$ day, whereas it was significantly $(P<0.05)$ lowered, to $2.35 \pm 0.212$ and $2.03 \pm 0.014 \mathrm{~mm} /$ day, under 75 and $100 \mu \mathrm{g} / \mathrm{ml} \mathrm{CH}$, respectively. In the presence of strain BS001, these growth rates were $2.75 \pm 0.20$ and $2.1 \pm 0.08 \mathrm{~mm} /$ day at 75 and $100 \mu \mathrm{g} / \mathrm{ml}$ $\mathrm{CH}$, respectively. Clearly, although these positive effects of strain BS001 persisted up to day 21, they were never significant $(P>0.05)$.

\section{DISCUSSION}

Several members of the genus Burkholderia, including Burkholderia terrae, have been reported to be enriched in the mycosphere of fungi such as Laccaria proxima and Lyophyllum sp. strain Karsten in soil (Warmink and van Elsas, 2008, 2009). These Burkholderia strains apparently utilize the hyphal network that such soil fungi form as a colonizable surface (Warmink and van Elsas, 2009). In eco-evolutionary terms, we postulated in earlier work that the Burkholderia terrae and related bacterial types that were enriched from soil by the hyphae of soil fungi (in the mycosphere) may find their ecological niche at the surfaces of such fungi, as driven by nutritional and colonization demands.

A clear facet of the association of such bacteria with mycelial networks in soil is the fungal facilitation of passage of air-filled voids in the soil (De Boer et al., 2005). This allows soil bacteria, for which great barriers exist in terms of their movement through soil, to access and explore new microhabitats which may be millimeters to centimeters away (Kohlmeier et al., 2005; Furuno et al., 2010; Nazir et al., 2010). Interestingly, our prime bacterial migrator, Burkholderia terrae strain BS001, was shown to not only migrate itself but also to enable other bacteria, like D. japonica BS003, to move along the fungal highway (Warmink et al., 2011). This led to the hypothesis that local conditions, in the form of colonizable surface structures and/or water maintenance conditions, were modulated to such an extent that the movement of other bacteria that are able to make use of the modified conditions became possible. Such conditions are typically found at cell aggregates that may form at the fungal surface, a feature we showed earlier for the Burkholderia terrae BS001 Lyophyllum sp. strain Karsten association (Warmink and van Elsas, 2009).

We here extend the detection of bacterial agglomerates along extending fungal hyphae in soil to a range of other fungi (Figure 1). By its capacity to live in close association with fungal hyphae and produce biofilm-type associations (as confirmed here for several fungal hosts), Burkholderia terrae BS001 has probably developed an optimal capacity to capture and utilize the compounds that are locally available, be these fungal-released or not. Using liquid media, strain BS001 has previously been found to induce the release of glycerol from the hyphae of Lyophyllum sp. strain Karsten, a compound that it can utilize for its own growth and survival (Nazir et al., 2013). However, to date we ignore the putative nutritional interaction of strain BS001 with the other test fungi used in this study.

Here, we provide evidence for the contention that Burkholderia terrae BS001 has a broad capacity to migrate along with the hyphae of a range of soil fungi, belonging to different genera and ecological classes, that are able to explore the $(\mathrm{G})$ soil in the microcosm set-up that was used. Hence, the fungal-interactive functions of strain BS001, which may include cellular appendices such as the type 3 secretion pilus, flagella and type 4 pili (Haq et al., 2014), are not highly specific for just one colonizable fungal host. Moreover, the different fungi that were conducive to strain BS001 comigration allowed the outgrowth of the bacterium along with the fungal hyphae, albeit to different population densities. Clearly, next to the reference fungus Lyophyllum sp. strain Karsten, another four (out of six) fungal hosts allowed outgrowth of strain BS001 to high population densities. On the basis of the thus presumed broad fungal-interactive capacity, we surmised that Burkholderia terrae strain BS001 has evolved toward a superior fitness in terms of the exploration of soil microhabitats in conjunction with diverse soil fungi that are locally encountered. This broad capacity is likely to be multi-faceted and may include a diversity of bacterial mechanisms, as detailed in Haq et al. (2014). In a generic sense, it likely includes the physical ability of strain BS001 to produce biofilm-like cell agglomerates associated with the hyphal networks just like the recently reported association of Bacillus subtilis with Aspergillus niger (Benoit et al., 2014). Unfortunately, we could not show this to occur directly in the soil as a result of technical difficulties. However, using the simplified cover slip based "soil-derived" systems, cell agglomerates or layers were indeed found to be formed by strain BS001 at different fungi. Although we did not reveal fully blown biofilms, we hypothesize that the typical biofilm formation pel and pga gene clusters that were recently found to be present on the Burkholderia terrae BS001 genome (Haq et al., 2014) may have been involved.

Moreover, it was very interesting to observe that, whereas Burkholderia terrae BS001 on the one hand obtains a benefit from its association with a fungal host, on the other hand, it appears to protect its partner against antagonists like Pseudomonas fluorescens strain CHA0 and/or its metabolome, present in its microhabitat. In natural soils, many (bacterial or fungal) antagonists exist that can inhibit fungal growth and survival as a result of the production of secondary metabolites (Keel et al., 1992). Hence, our finding of protection against such agents by bacterial colonizers of fungal surfaces is of major importance, as it adds a concrete ecological phenomenon to existing theories about soil microbial interactomes.

To nail down the mechanism of protection, we performed experiments with the antifungal compound cycloheximide $(\mathrm{CH})$, which can be produced in soil by bacteria of the genus Streptomyces (Abou-Zeid and El-Sherbini, 1975; Kominek, 1975a,b; Dykstra and Wang, 1990). The analyses indicated that Burkholderia terrae $\mathrm{BS} 001$ indeed can provide protection, potentially via shielding/sorption or detoxification effects, from $\mathrm{CH}$ to several of the fungi, at different levels of $\mathrm{CH}$. Protection of fungi like Rhizoctonia solani AG3, T. asperellum 302, and/or Lyophyllum sp. strain Karsten by Burkholderia terrae BS001 against antifungal agents has great practical relevance. It may explain why, for example, plant disease management may fail or does not fully work in nature given the possibility that target plant-pathogenic fungi may have acquired bacterial protection much like that found in our study. Furthermore, and adding to the practical relevance, the efficiency 
of some biocontrol agents against plant disease might be improved by making use of a protective strategy, i.e., by combining a biocontrol fungus, such as the here-used T. asperellum 302, with the protective bacterium Burkholderia terrae BS001.

We propose that the protection is related to the activity of the cell agglomerates that are formed by Burkholderia terrae BS001 around the fungal hyphae. The bacterium, in its interactive behavior, when allowed to complete its associative process, may build a matrix composed of compounds such as extracellular polysaccharides at the fungal surface. Such a matrix may shield away some of the antifungal agents/compounds that are present in the vicinity. Alternatively, the antifungal agents are inactivated by a (bio)chemical transformation activity. Thus, the Burkholderia terrae strain BS001 cells around fungal mycelia may act as agents that counteract antifungal agents. The barrier could be physicochemical or biochemical, as antifungal compounds may be bound to, or inactivated by, the cell agglomerates at the fungus, thus becoming unavailable to the growing fungus. A potential effect of Burkholderia terrae $\mathrm{BS} 001$ on $\mathrm{CH}$ might be related to the local $\mathrm{pH}$ (data not shown), as $\mathrm{CH}$ may become unstable at higher $\mathrm{pH}$ levels (Lawes, 1962).

In the light of the current data on strain BS001 effects, we propose that (1) Burkholderia terrae BS001 is a generalist rather than a specialist in terms of its capacity to interact with mycelial fungi in soil, and (2) that its interaction with these soil fungi may be mutualistic rather than commensalistic. However, there is a paucity of knowledge on the mechanisms used by the bacterial as well as fungal partners in the associations. Hence, further in-depth research in this area is strongly advocated.

\section{AUTHOR CONTRIBUTIONS}

Rashid Nazir and Jan Dirk van Elsas contributed to the conception and design of the work, drafting the work and revising it critically for important intellectual contents. Rashid Nazir and Diana I. Tazetdinova contributed in acquisition, analysis and interpretation of data for the work presented in this manuscript. Jan Dirk van Elsas and Rashid Nazir collectively worked on final approval of the version to be published. All three authors agreed to be accountable for all aspects of the work for the accuracy and/or integrity.

\section{ACKNOWLEDGMENTS}

We gratefully acknowledge the provision of fungal strains i.e., wood rot and Fusarium spp. from Prof. Dr. Lynn Boddey and Prof. Dr. Philippe Lemanceau, respectively. Rashid Nazir was financially supported by the HEC program of the government of Pakistan. He was further assisted by the Soil Biotechnology Foundation.

\section{SUPPLEMENTARY MATERIAL}

The Supplementary Material for this article can be found online at: http://www.frontiersin.org/journal/10.3389/fmicb.2014.00598/ abstract

\section{REFERENCES}

Abou-Zeid, A. A., and El-Sherbini, S. H. (1975). Fermentative production of cycloheximide by Streptomyces griseus and Streptomyces noursei. J. Appl. Chem. Biotech. 24, 283-291.
Banitz, T., Fetzer, I., Johst, K., Wick, L. Y., Harms, H., and Frank, K. (2011a). Assessing biodegradation benefits from dispersal networks. Ecol. Modell. 222, 2552-2560. doi: 10.1016/j.ecolmodel.2010.07.005

Banitz, T., Wick, L. Y., Fetzer, I., Frank, K., Harms, H., and Johst, K. (2011b). Dispersal networks for enhancing bacterial degradation in heterogeneous environments. Environ. Pollut. 159, 2781-2788. doi: 10.1016/j.envpol.2011.05.008

Banitz, T., Johst, K., Wick, L. Y., Fetzer, I., Harms, H., and Frank, K. (2012). The relevance of conditional dispersal for bacterial colony growth and biodegradation. Microb. Ecol. 63, 339-347. doi: 10.1007/s00248-011-9927-3

Banitz, T., Johst, K., Wick, L. Y., Schamfuß, S., Harms, H., and Frank, K. (2013). Highways versus pipelines: contributions of two fungal transport mechanisms to efficient bioremediation. Environ. Microbiol. Rep. 5, 211-218. doi: 10.1111/17582229.12002

Benoit, I., van den Esker, M. H., Patyshakuliyeva, A., Mattern, D. J., Blei, F., Zhou, M., et al. (2014). Bacillus subtilis attachment to Aspergillus niger hyphae results in mutually altered metabolism. Environ. Microbiol. doi: 10.1111/1462-2920.12564

De Boer, W. D., Folman, L. B., Summerbell, R. C., and Boddy, L. (2005). Living in a fungal world: impact of fungi on soil bacterial niche development. FEMS Microbiol. Rev. 29, 795-811. doi: 10.1016/j.femsre.2004.11.005

Dykstra, K. H., and Wang, H. Y. (1990). Feedback regulation and the intracellular protein profile of Streptomyces griseus in a cycloheximide fermentation. Appl. Microbiol. Biotech. 34, 191-197. doi: 10.1007/BF001 66779

Furuno, S., Foss, S., Wild, E., Jones, K. C., Semple, K. T., Harms, H., et al. (2012a). Mycelia promote active transport and spatial dispersion of polycyclic aromatic hydrocarbons. Environ. Sci. Technol. 46, 5463-5470. doi: 10.1021/es300810b

Furuno, S., Remer, R., Chatzinotas, A., Harms, H., and Wick, L. Y. (2012b). Use of mycelia as paths for the isolation of contaminant-degrading bacteria from soil. Microb. Biotechnol. 5, 142-148. doi: 10.1111/j.1751-7915.2011.00309.x

Furuno, S., Päzolt, K., Rabe, C., Neu, T. R., Harms, H., and Wick, L. Y. (2010). Fungal mycelia allow chemotactic dispersal of polycyclic aromatic hydrocarbondegrading bacteria in water-unsaturated systems. Environ. Microbiol. 12, 13911398. doi: 10.1111/j.1462-2920.2009.02022.x

Gould, W. D., Hagedorn, C., Bardinelli, T. R., and Zablotowicz, R. M. (1985). New selective media for enumeration and recovery of fluorescent pseudomonads from various habitats. Appl. Environ. Microbiol. 49, 28-32.

Haq, I. U., Graupner, K., Nazir, R., and van Elsas, J. D. (2014). The genome of the fungal-interactive soil bacterium Burkholderia terrae BS001 - a plethora of outstanding interactive capabilities unveiled. Genome. Biol. Evol. 6, 1652-1668. doi: 10.1093/gbe/evu126

Harms, H., Schlosser, D., and Wick, L. Y. (2011). Untapped potential: exploiting fungi in bioremediation of hazardous chemicals. Nat. Rev. Microbiol. 9, 177-192. doi: 10.1038/nrmicro2519

Johansson, J. F., Paul, L. R., and Finlay, R. D. (2004). Microbial interactions in the mycorrhizosphere and their significance for sustainable agriculture. FEMS Microbiol. Ecol. 48, 1-13. doi: 10.1016/j.femsec.2003. 11.012

Keel, C., Schnider, U., Maurhofer, M., Voisard, C., Laville, J., Burger, U., et al. (1992). Suppression of root diseases by Pseudomonas fluorescens CHA0: importance of the bacterial secondary metabolite 2,4-diacetylphloroglucinol. Mol. Plant Microb. Int. 5, 4-13. doi: 10.1094/MPMI-5-004

Kohlmeier, S., Smits, T. H. M., Ford, R. M., Keel, C., Harms, H., and Wick, L. Y. (2005). Taking the fungal highway: mobilization of pollutantdegrading bacteria by fungi. Environ. Sci. Tech. 39, 4640-4646. doi: 10.1021/es $047979 z$

Kominek, L. A. (1975a). Cycloheximide production by Streptomyces griseus: alleviation of end-product inhibition by dialysis-extraction fermentation. Antimicrob. Agents Chemother. 7, 861-863. doi: 10.1128/AAC.7.6.861

Kominek, L. A. (1975b). Cycloheximide production by Streptomyces griseus: control mechanisms of cycloheximide biosynthesis. Antimicrob. Agents Chemother. 7, 856-860. doi: 10.1128/AAC.7.6.856

Lackner, G., Möbius, N., Scherlach, K., Partida-Martinez, L. P., Winkler, R., Schmitt, I., et al. (2009). Global distribution and evolution of a toxinogenic Burkholderia-Rhizopus symbiosis. Appl. Environ. Microbiol. 75, 2982-2986. doi: 10.1128/AEM.01765-08

Lawes, B. C. (1962). Absolute configuration of cycloheximide from thermal degradation. J. Am. Chem. Soc. 84, 239-244. doi: 10.1021/ja00861a022

Nazir, R., Warmink, J. A., Boersma, H., and van Elsas, J. D. (2010). Mechanisms that promote bacterial fitness in fungal-affected soil microhabitats. 
FEMS Microbiol. Ecol. 71, 169-185. doi: 10.1111/j.1574-6941.2009. 00807.x

Nazir, R., Warmink, J. A., Voordes, D. C., van de Bovenkamp, H. H., and van Elsas, J. D. (2013). Inhibition of mushroom formation and induction of glycerol release-ecological strategies of Burkholderia terrae BS001 to create a hospitable niche at the fungus Lyophyllum sp. strain Karsten. Microb. Ecol. 65, 245-254. doi: 10.1007/s00248-012-0100-4

Nazir, R., Zhang, M., de Boer, W., and van Elsas, J. D. (2012). The capacity to comigrate with Lyophyllum sp. strain Karsten through different soils is spread among several phylogenetic groups within the genus Burkholderia. Soil Biol. Biochem. 50, 221-233. doi: 10.1016/j.soilbio.2012.03.015

Partida-Martinez, L. P., de Looss, C. F., Ishida, K., Ishida, M., Roth, M., Buder, K., et al. (2007a). Rhizonin, the first mycotoxin isolated from the zygomycota, is not a fungal metabolite but is produced by bacterial endosymbionts. Appl. Environ. Microbiol. 73, 793-797. doi: 10.1128/AEM.01784-06

Partida-Martinez, L. P., Groth, I., Schmitt, I., Richter, W., Roth, M., and Hertweck, C. (2007b). Burkholderia rhizoxinica sp. nov. and Burkholderia endofungorum sp. nov., bacterial endosymbionts of the plant-pathogenic fungus Rhizopus microsporus. Int. J. Syst. Evol. Microbiol. 57, 2583-2590. doi: 10.1099/ijs.0.64660-0

Partida-Martinez, L. P., Monajembashi, S., Greulich, K. O., and Hertweck, C. (2007c). Endosymbiont-dependent host reproduction maintains bacterial-fungal mutualism. Curr. Biol. 17, 773-777. doi: 10.1016/j.cub.2007.03.039

Partida-Martinez, L. P., and Hertweck, C. (2005). Pathogenic fungus harbours endosymbiotic bacteria for toxin production. Nature 437, 884-888. doi: 10.1038 /nature03997

Pion, M., Spangenberg, J. E., Simon, A., Bindschedler, S., Flury, C., Chatelain, A., et al. (2013). Bacterial farming by the fungus Morchella crassipes. Proc. Biol. Sci. 280, 2242. doi: 10.1098/rspb.2013.2242

Roelants, F. M., Torrance, P. D., Bezman, N., and Thorner, J. (2002). Pkhl and $\mathrm{Pkh} 2$ differentially phosphorylate and activate Ypk1 and Ykr2 and define protein kinase modules required for maintenance of cell wall integrity. Mol. Biol. Cell 13, 3005-3028. doi: 10.1091/mbc.E02-04-0201

Salles, J. F., Samyn, E., Vandamme, P., van Veen, J. A., and van Elsas, J. D. (2005). “The diversity of culturable Burkholderia species in soil is driven by changes in agricultural management," in Burkholderia Community Structure in Soils Under Different Agricultural Management, ed. J. F. Salles (Netherlands: Leiden University), 71-93.

Schamfuß, S., Neu, T. R., Harms, H., van der Meer, J. R., Tecon, R., and Wick, L. Y. (2013). Mycelial networks enhance the bioavailability of PAH in water unsaturated environments. Environ. Sci. Technol. 47, 6908-6915. doi: $10.1021 /$ es304378d
Suárez-Moreno, Z. R., Caballero-Mellado, J., Coutinho, B. G., Mendonça-Previato, L., James, E. K., and Venturi, V. (2012). Common features of environmental and potentially beneficial plant-associated Burkholderia. Microb. Ecol. 63, 249-266. doi: 10.1007/s00248-011-9929-1

Warmink, J. A., Nazir, R., Corten, B., and van Elsas, J. D. (2011). Hitchhikers on the fungal highway: the helper effect for bacterial migration via fungal hyphae. Soil Biol. Biochem. 43, 760-765. doi: 10.1016/j.soilbio.2010. 12.009

Warmink, J. A., and van Elsas, J. D. (2008). Selection of bacterial populations in the mycosphere of Laccaria proxima: is type III secretion involved? ISME J. 2, 887-900. doi: 10.1038/ismej.2008.41

Warmink, J. A., and van Elsas, J. D. (2009). Migratory response of soil bacteria to Lyophyllum sp. strain Karsten in soil microcosms. Appl. Environ. Microb. 75, 2820-2830. doi: 10.1128/AEM.02110-08

Wick, L. Y., Furuno, S., and Harms, H. (2010). "Fungi as transport vectors for contaminants and contaminant-degrading bacteria," in Handbook of Hydrocarbon and Lipid Microbiology, eds K. Timmis, T. McGenity, J. R. van der Meer, and V. de Lorenzo (New York, NY: Springer-Verlag Berlin Heidelberg), 1555-1561.

Wick, L. Y., Remer, R., Würz, B., Reichenbach, J., Braun, S., Schäfer, F., et al. (2007). Effect of fungal hyphae on the access of bacteria to phenanthrene in soil. Environ. Sci. Technol. 41, 500-505. doi: 10.1021/es061407s

Conflict of Interest Statement: The authors declare that the research was conducted in the absence of any commercial or financial relationships that could be construed as a potential conflict of interest.

Received: 28 August 2014; accepted: 22 October 2014; published online: 11 November 2014.

Citation: Nazir R, Tazetdinova DI and van Elsas JD (2014) Burkholderia terrae BS001 migrates proficiently with diverse fungal hosts through soil and provides protection from antifungal agents. Front. Microbiol. 5:598. doi: 10.3389/fmicb.2014.00598

This article was submitted to Terrestrial Microbiology, a section of the journal Frontiers in Microbiology.

Copyright (c) 2014 Nazir, Tazetdinova and van Elsas. This is an open-access article distributed under the terms of the Creative Commons Attribution License (CC BY). The use, distribution or reproduction in other forums is permitted, provided the original author(s) or licensor are credited and that the original publication in this journal is cited, in accordance with accepted academic practice. No use, distribution or reproduction is permitted which does not comply with these terms. 